\title{
Vaccine design of coronavirus spike (S) glycoprotein in chicken: immunoinformatics and computational approaches
}

\author{
Eman A. Awadelkareem ${ }^{1}$ and Sumaia A. Ali $^{2^{*}}$ D
}

\begin{abstract}
Background: Infectious bronchitis (IB) is a highly contagious respiratory disease in chickens and produces economic loss within the poultry industry. This disease is caused by a single stranded RNA virus belonging to Cronaviridae family. This study aimed to design a potential multi-epitopes vaccine against infectious bronchitis virus spike protein (S). Protein characterization was also performed for IBV spike protein.

Methods: The present study used various tools in Immune Epitope Database (IEDB) to predict conserved B and T cell epitopes against IBV spike (S) protein that may perform a significant role in provoking the resistance response to IBV infection.

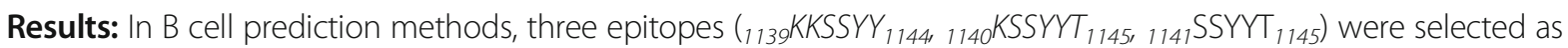
surface, linear and antigenic epitopes.

Many $\mathrm{MHCl}$ and $\mathrm{MHCll}$ epitopes were predicted for IBV S protein. Among them ${ }_{982} \mathrm{YYITARDMY}_{990}$ and ${ }_{983} \mathrm{YITARDMYM}_{991}$ epitopes displayed high antigenicity, no allergenicity and no toxicity as well as great linkage with $\mathrm{MHCl}$ and $\mathrm{MHCll}$ alleles. Moreover, docking analysis of $\mathrm{MHCl}$ epitopes produced strong binding affinity with $\mathrm{BF}_{2}$ alleles.

Conclusion: Five conserved epitopes were expected from spike glycoprotein of IBV as the best B and T cell epitopes due to high antigenicity, no allergenicity and no toxicity. In addition, MHC epitopes showed great linkage with MHC alleles as well as strong interaction with BF2 alleles. These epitopes should be designed and incorporated and then tested as multi-epitope vaccine against IBV.
\end{abstract}

Keywords: IBV, Spike protein, B-and T-cell epitopes, Computational approaches, Vaccine design

\section{Introduction}

Infectious bronchitis virus (IBV) is a single Positive stranded RNA that belonging to coronavirus of the chicken (Gallus gallus). It's a highly contagious respiratory disease in chickens that's mainly severe for very young chicks. The signs of illness include tracheal rales, coughing, sneezing, nasal discharge and some strains may cause kidney damage $[1,2]$. The disease can be transmitted in

\footnotetext{
* Correspondence: somiahadlool@yahoo.com

${ }^{2}$ Department of Veterinary Medicine and Surgery, College of Veterinary Medicine, Sudan University of Science and Technology, Khartoum, Sudan Full list of author information is available at the end of the article
}

respiratory discharges and feces by infected chickens, and it is spread by aerosol, ingestion of contaminated feed and water, and contact with contaminated equipment or clothing. The virus is not transmitted via eggs [3]. The disease causes economic loss within the poultry industry, affecting the performance of meat-type and egg-laying birds. The disease can affect all ages, but the clinical disease is more severe in young chicks. Chicks become more resistant to IBV-induced mortality with the increasing age [4].

There are four structural proteins related to the envelope, the spike (S), membrane $(M)$, envelope (E), and nucleocapsid $(\mathrm{N})$ protein [5]. The spike 'S' glycoprotein which located

(c) The Author(s). 2020 Open Access This article is licensed under a Creative Commons Attribution 4.0 International License, which permits use, sharing, adaptation, distribution and reproduction in any medium or format, as long as you give appropriate credit to the original author(s) and the source, provide a link to the Creative Commons licence, and indicate if changes were made. The images or other third party material in this article are included in the article's Creative Commons licence, unless indicated otherwise in a credit line to the material. If material is not included in the article's Creative Commons licence and your intended use is not permitted by statutory regulation or exceeds the permitted use, you will need to obtain permission directly from the copyright holder. To view a copy of this licence, visit http://creativecommons.org/licenses/by/4.0/ 
Table 1 Accession numbers, date and area of collection of the retrieved sequences of Spike protein of IBV

\begin{tabular}{|c|c|c|c|c|c|c|c|}
\hline No & Accession No & Country & Year & No & Accession No & Country & Year \\
\hline 1 & NP_040831. $1^{\mathrm{a}}$ & UK & 2018 & 47 & AAV98206.1 & USA & 2002 \\
\hline 2 & AHX25911.1 & China & 2016 & 48 & AVX27612.1 & India & 2004 \\
\hline 3 & AHX25902.1 & China & 2016 & 49 & ALE71331.1 & India & 2018 \\
\hline 4 & AHX25893.1 & China & 2016 & 50 & AJP16712.1 & China & 2015 \\
\hline 5 & AMK51938.1 & China & 2016 & 51 & AJP16739.1 & China & 2015 \\
\hline 6 & AEP84746.1 & China & 2016 & 52 & AFP50306.1 & Korea & 2015 \\
\hline 7 & AEP84736.1 & China & 2016 & 53 & AFP50302.1 & Korea & 2012 \\
\hline 8 & ACX71849.1 & China & 2011 & 54 & AFP50294.1 & Korea & 2012 \\
\hline 9 & ACX71844.1 & China & 2011 & 55 & AFP50274.1 & Korea & 2012 \\
\hline 10 & ACX71842.1 & China & 2011 & 56 & AEL12221.1 & China & 2012 \\
\hline 11 & AAU09490.1 & China & 2011 & 57 & ADY62552.1 & China & 2012 \\
\hline 12 & AAY24433.1 & Singapore & 2005 & 58 & ADV71785.1 & Netherlands & 2010 \\
\hline 13 & AAY24423.1 & Singapore & 2005 & 59 & ACQ55230.1 & Netherlands & 2011 \\
\hline 14 & AAY21248.1 & Singapore & 2005 & 60 & ARE67884.1 & Pakistan & 2017 \\
\hline 15 & AAY21247.1 & Singapore & 2005 & 61 & ARB66180.1 & China & 2017 \\
\hline 16 & AAY21246.1 & Singapore & 2005 & 62 & AQY55821.1 & China & 2017 \\
\hline 17 & AAY21245.1 & Singapore & 2005 & 63 & AHX26172.1 & China & 2016 \\
\hline 18 & AAY21244.1 & Singapore & 2005 & 64 & AHX26163.1 & China & 2016 \\
\hline 19 & AAY21243.1 & Singapore & 2005 & 65 & AHX26154.1 & China & 2016 \\
\hline 20 & AAY21242.1 & Singapore & 2005 & 66 & AHX26145.1 & China & 2016 \\
\hline 21 & AGW24533.1 & India & 2015 & 67 & AHX26136.1 & China & 2016 \\
\hline 22 & AAW33786.1 & USA & 2006 & 68 & AHX26127.1 & China & 2016 \\
\hline 23 & AER08740.1 & Sweden & 2012 & 69 & AHX26118.1 & China & 2016 \\
\hline 24 & AER08739.1 & Sweden & 2012 & 70 & AHX26109.1 & China & 2016 \\
\hline 25 & AER08729.1 & Sweden & 2012 & 71 & AHX26073.1 & China & 2016 \\
\hline 26 & AER08728.1 & Sweden & 2012 & 72 & AHX26064.1 & China & 2016 \\
\hline 27 & AER08727.1 & Sweden & 2012 & 73 & AHX26055.1 & China & 2016 \\
\hline 28 & AER08726.1 & Sweden & 2012 & 74 & AHX26046.1 & China & 2016 \\
\hline 29 & AER08725.1 & Sweden & 2012 & 75 & AHX26037.1 & China & 2016 \\
\hline 30 & AER08724.1 & Sweden & 2012 & 76 & AHX26028.1 & China & 2016 \\
\hline 31 & AER08723.1 & Sweden & 2012 & 77 & AHX26019.1 & China & 2016 \\
\hline 32 & AER08722.1 & Sweden & 2012 & 78 & AHX26010.1 & China & 2016 \\
\hline 33 & AER08721.1 & Sweden & 2012 & 79 & AHX26001.1 & China & 2016 \\
\hline 34 & ADA83557.1 & USA & 2011 & 80 & AHX25992.1 & China & 2016 \\
\hline 35 & ADA83467.1 & USA & 2011 & 81 & AHX25983.1 & China & 2016 \\
\hline 36 & ABH01142.1 & USA & 2007 & 82 & AHX25974.1 & China & 2016 \\
\hline 37 & ABH01141.1 & USA & 2007 & 83 & AHX25965.1 & China & 2016 \\
\hline 38 & ABI26423.1 & USA & 2006 & 84 & AHX25956.1 & China & 2016 \\
\hline 39 & AAK27168.1 & China & 2005 & 85 & AHX25947.1 & China & 2016 \\
\hline 40 & $\mathrm{ACH} 72794.1$ & China & 2009 & 86 & AHX25938.1 & China & 2016 \\
\hline 41 & AAW83034.1 & China & 2006 & 87 & AHX25929.1 & China & 2016 \\
\hline 42 & ARS23139.1 & Egypt & 2014 & 88 & ACJ50199.1 & Singapore & 2005 \\
\hline 43 & AHX25920.1 & China & 2016 & 89 & ACO37566.1 & Singapore & 2005 \\
\hline 44 & ADP06504.1 & USA & 2012 & 90 & AYG86360.1 & SouthKorea & 2018 \\
\hline 45 & AAA66578.1 & UK & 1995 & 91 & AYG86347.1 & SouthKorea & 2018 \\
\hline 46 & AAA70235.1 & USA & 2002 & 92 & AAV28722.1 & China & 2006 \\
\hline
\end{tabular}


at the surface of the virion. The membrane ' $M$ ' glycoprotein is partially exposed at the surface of the virion and also the nucleocapsid ' $\mathrm{N}$ ' protein that located internally. The spike glycoprotein of IBV induces virus neutralizing (VN) and $\mathrm{HI}$ antibodies and has been considered as the most likely inducer of protection $[2,4]$. The $S$ protein is either a dimer or trimer. It has two recognized functions; binding the virus to receptor molecules on host cells, and activating fusion of the virion membrane with host cell membranes, releasing the viral genome into the cell [2]. The spike gene in particular the S1 part, is highly variable, due to insertions, deletions, substitutions and recombination events [6]. Application of vaccine is the most effective way to protect against pathogenic diseases, particularly when these pathogens have a high mortality rate such as IBV and viruses in general. On the other hand, the large number of serotypes and strains (genotype) of IBV specifically complicate control method. IBV has shift and drift property [7].
Inactivated and live-attenuated vaccines are employed to control the disease. However, inactivated vaccines often fail to induce strong cellular immunity, while liveattenuated vaccines can contribute to development of antigenic variant viruses [5]. The increasing number of new IBV serotypes, caused by frequent gene mutation and recombination, poses a major challenge for the prevention and control of infectious bronchitis disease [8].

RNA viruses such as IBV have high mutational rates. Thus, the most important step in the design of crossprotective peptide vaccine against IBV is to target the conserved epitopes of different IBV serotypes [5].

Presentation by MHC molecules is important for developing vaccinal immunity. MHC class I and class II molecules are typically highly polymorphic and polygenic [9]. Avian MHC class I and class II genes are localized into two regions (MHC-B and MHC-Y) on the chromosome 16. The MHC-B and MHC-Y haplotypes assort independently as the result of an intervening

(a)

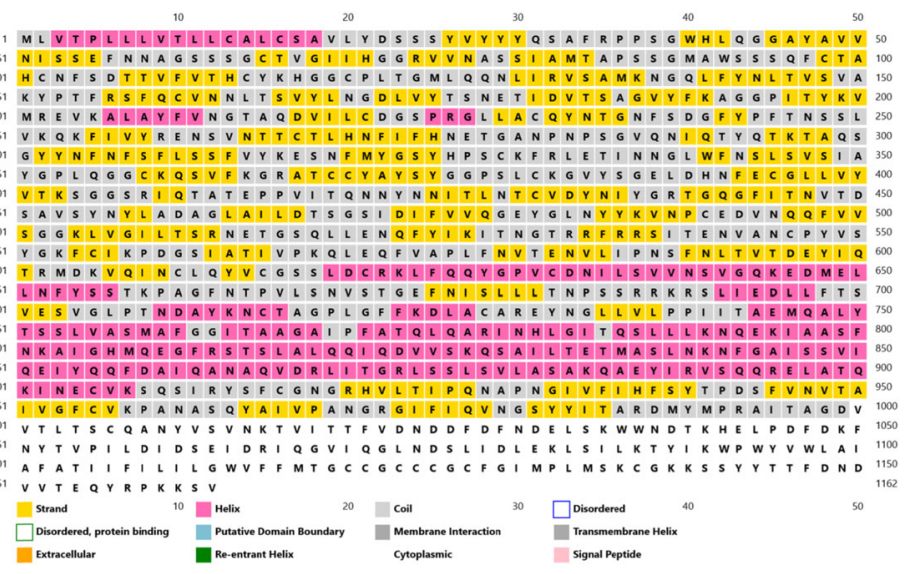

(b)

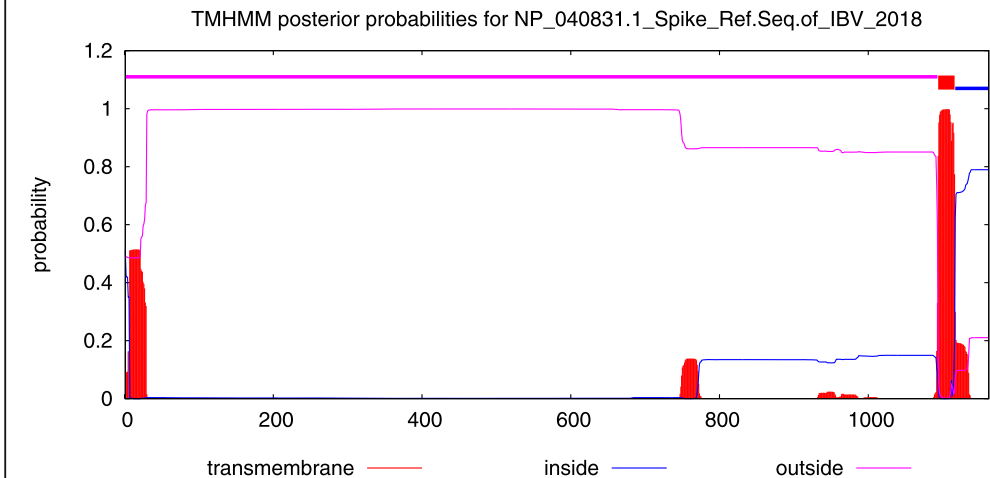

(c)

\begin{tabular}{|c|c|}
\hline \multicolumn{2}{|c|}{ Predicted bonds } \\
\hline $13-358$ & LVTLLLCALCSA - PLQGGCKQSVF \\
\hline $16-267$ & LLCALCSAVLY - SVNTTCTLLHNF \\
\hline $65-120$ & GSSSCCTVGII - YKHGGCPLTGM \\
\hline $98-610$ & SSSQFCTAHCN - KVQINCLQYVC \\
\hline $102-431$ & FCTAHCNFDT - ITLNTCVDYNI \\
\hline $114-395$ & VFVTHCYKHGG - DHNFEOGLL.VY \\
\hline $160-1121$ & FRSFQCVNNLT - FMTCCCCCCCG \\
\hline $221-370$ & QDVILCDGSPR - GRATCCYAYSY \\
\hline $231-632$ & RGL.LACQYNTG - QYGPVCDNILS \\
\hline $329-546$ & SYHPSCKFRLE - ENVANCPYVSY \\
\hline $369-905$ & KGRATCCYAYS - QKINECVKSQS \\
\hline $381-916$ & GGPSLCCKGVYS - IRYSFCGNGRH \\
\hline $491-1123$ & YKVNPCEDVNQ - TGCCGCCCCCF \\
\hline $555-1137$ & SYGKFCIKPDG - PLLMSKCGKKSS \\
\hline $615-728$ & CLQYVCCSSLD - FKDL.ACAREYN \\
\hline $621-1006$ & GSSLDCRKLLFQ - VTLTSCQANYV \\
\hline $715-955$ & DAYKNCTAGPL - AIVGFCVKPAN \\
\hline $1120-1125$ & FFMTGCCGCCC - CCGCCOCCFGI \\
\hline $1124-1127$ & GOOCOCOCCFG - GCCCGCFGIMP \\
\hline
\end{tabular}

Fig. 1 (a): The secondary structure of IBV spike protein; (b): transmembranr topology of spike protein; (c): the position of disulphides bond (S-S) in spike protein of IBV 
Table 2 Blastp similarity search of IBV against other coronaviruses in human and animals

\begin{tabular}{lllr}
\hline NCBI Protein ID & Protein Name & E-value & Identity \\
\hline YP_001941166.1 & Turkey coronavirus & 0.0 & $38.59 \%$ \\
YP_009194639.1 & Camel alphacoronavirus & $8 \mathrm{e}-126$ & $34.05 \%$ \\
YP_009199242.1 & Swine enteric coronavirus & $4 \mathrm{e}-124$ & $31.47 \%$ \\
YP_003767.1 & Human coronavirus NL63 & $2 \mathrm{e}-121$ & $34.01 \%$ \\
NP_598310.1 & Porcine epidemic diarrhea virus & $8 \mathrm{e}-120$ & $31.36 \%$ \\
YP_009273005.1 & Rousettus bat coronavirus & $1 \mathrm{e}-115$ & $32.86 \%$ \\
NP_058424.1 & Transmissible gastroenteritis virus & $2 \mathrm{e}-109$ & $32.03 \%$ \\
YP_209233.1 & Murine hepatitis virus strain JHM & $9 \mathrm{e}-109$ & $37.20 \%$ \\
YP_004070194.1 & Feline infectious peritonitis virus & $1 \mathrm{e}-108$ & $31.70 \%$ \\
YP_003858584.1 & Bat coronavirus BM48-31/BGR/2008 & $4 \mathrm{e}-107$ & $35.69 \%$ \\
NP_828851.1 & E2 glycoprotein precursor & $5 \mathrm{e}-107$ & $36.28 \%$ \\
YP_009724390.1 & Severe acute respiratory syndrome-related coronavirus] & $1 \mathrm{e}$ & 3106 \\
YP_009555241.1 & Severe acute respiratory syndrome coronavirus 2 & $3 \mathrm{e}-105$ & $31.42 \%$ \\
YP_009047204.1 & Human coronavirus OC43 & $2 \mathrm{e}-104$ & $34.71 \%$ \\
\hline
\end{tabular}

region that supports highly frequent recombination [9, 10]. Chicken MHC B-F molecules have been structurally and functionally related to mammalian MHC class I molecules and have been involved in the presentation of antigen to CD8 + T lymphocytes, which is important for antiviral immune response [11]. Recently, the design of epitope-based vaccines has been expanded by developments in genomics, proteomics and the understanding of pathogens. Epitope is the negligible immunogenic region of a sequence of proteins that specifically produces accurate immune responses [12]. The identification of specific $\mathrm{B}$ and $\mathrm{T}$ cell epitopes produced more desirable manipulation of immune response [13]. It is known that designing of multi-epitope vaccines using bioinformatics tools can significantly reduce the time and cost of production and produce satisfactory results $[14,15]$.

The production of safer and more reliable vaccines for controlling IBV is important. Therefore, the aim of this study is to analyze strains of spike (S) glycoprotein of infectious bronchitis virus reported in NCBI database

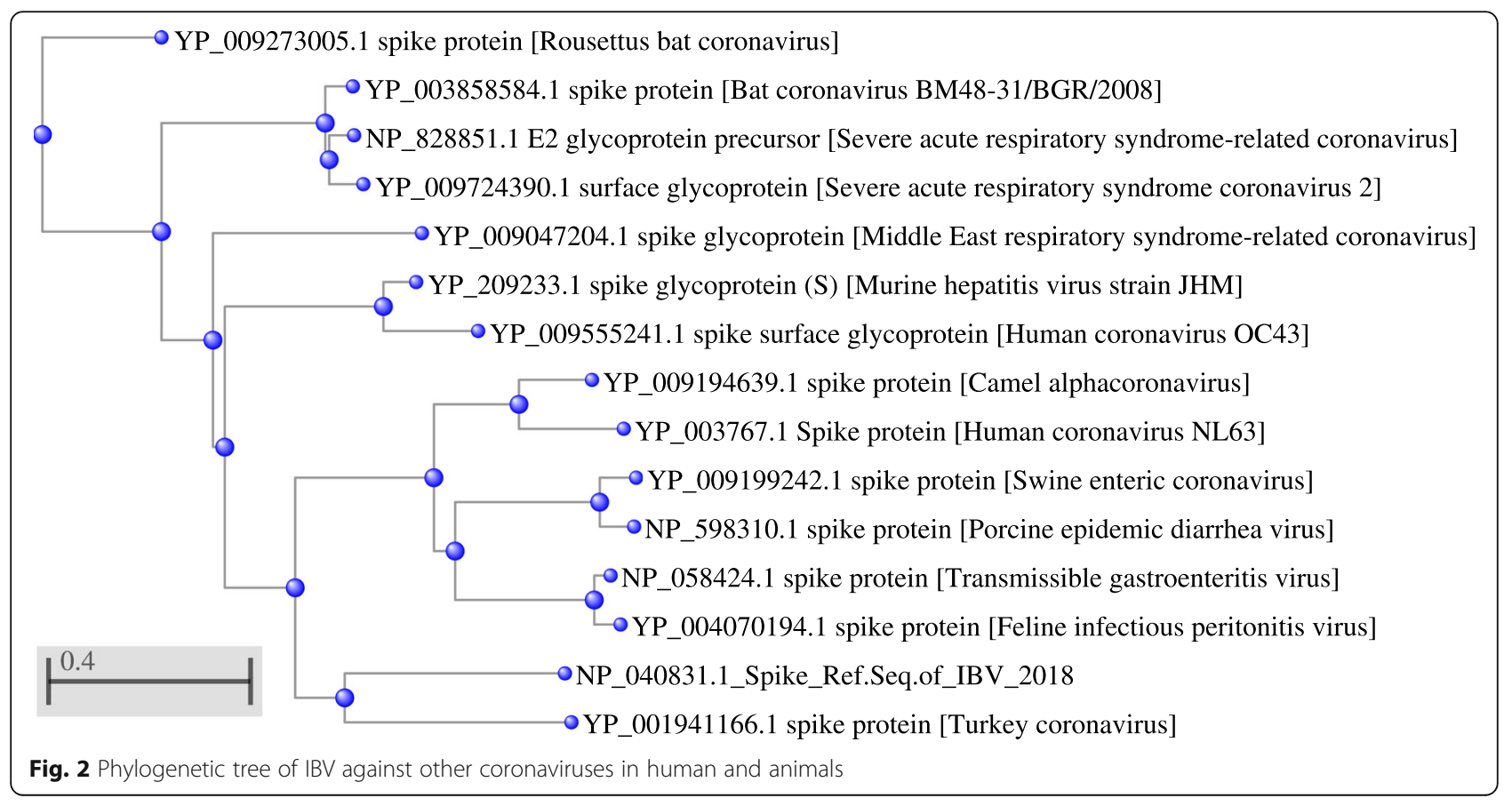




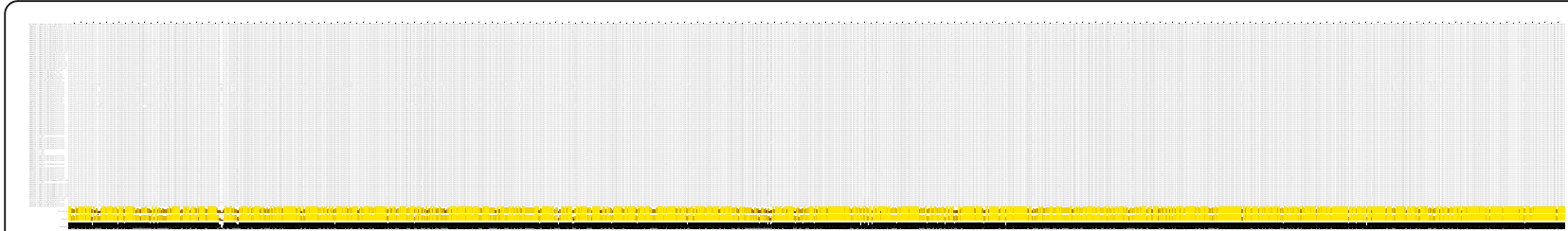

Fig. 3 Multiple sequence alignment of spike (S) protein of IBV visualized by Jalview 2.10.5. Yellow color bar and star sign indicate the full conservation. The brown region indicates the mismatched sequences among them. Black bars show the consensus logo sequence and yellow color indicates good quality

using immunoinformatics and computational approaches to select all possible epitopes that can be used as multi-epitopes vaccine. Protein characterization was also achieved for IBV spike protein.

\section{Material and method}

\section{Protein sequence retrieval}

Spike (S) protein sequences of different infectious bronchitis virus (IBV) strains were retrieved from the GeneBank of National Central Biotechnology Information (NCBI) (http://www.ncbi.nlm.nih.gov/protein/) database in March 2019. The sequences were saved in FASTA format (Table 1).

\section{Structural analysis}

Reference sequence of spike S protein (NP_040831.1) was analyzed to identify chemicals and physical properties including GRAVY (grand average of hydropathicity), half-life, molecular weight, stability index and amino acids atomic composition using an online tool Protparam [16]

Secondary structure of spike S protein of IBV was analyzed through PSIPRED [17]. The secondary structure of protein including helix, sheet, turn, and coil parameters was predicted using GOR IV server at https://npsaprabi.ibcp.fr/cgi-bin/secpred_sopma.pl. TMHMM an online tool (http://www.cbs.dtu.dk/services/TMHMM/),

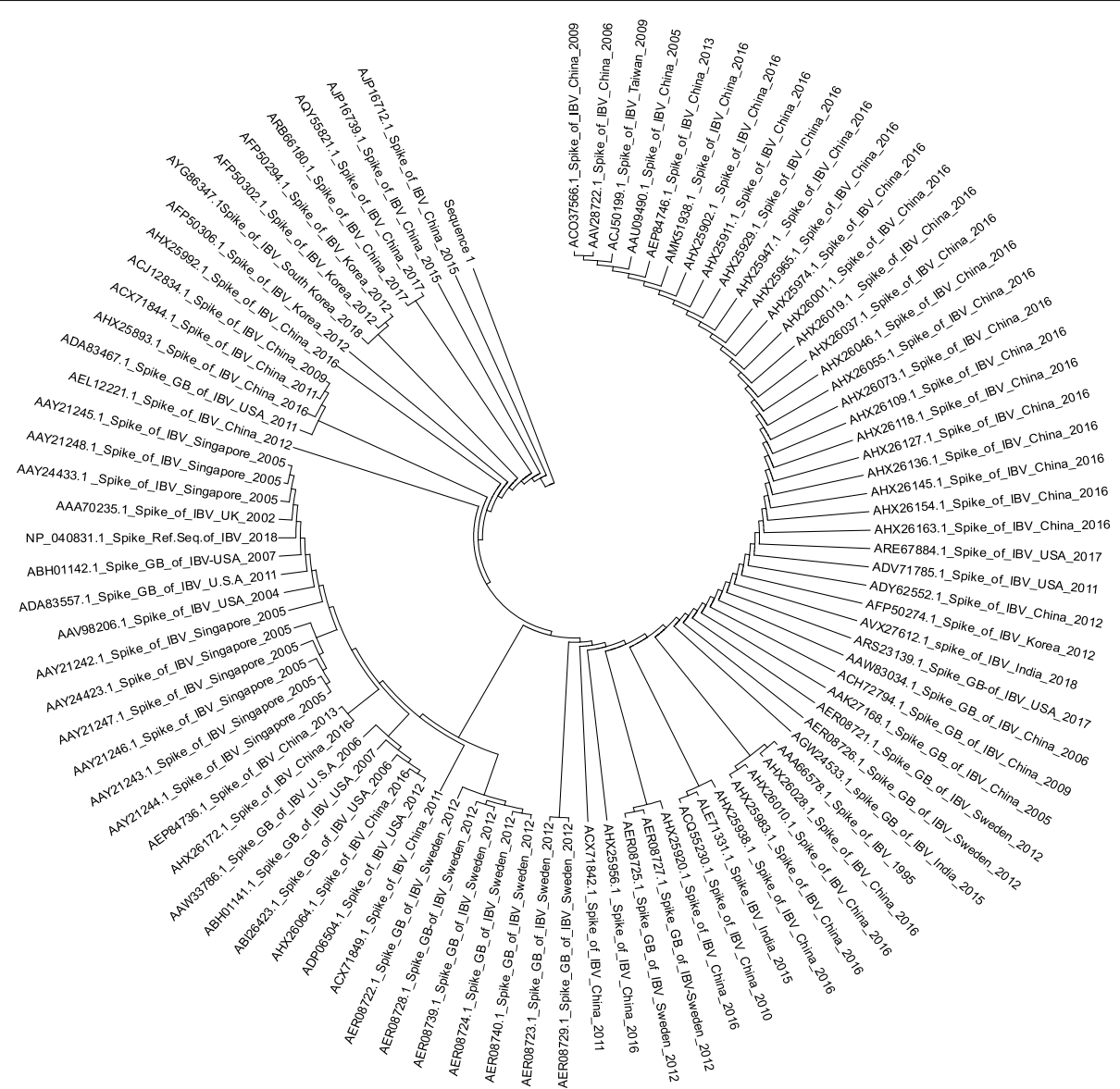

Fig. 4 Phylogenetic tree of retrieved strains of spike protein using MEGA7.0.26 software 
Table $\mathbf{3}$ Conservancy assessment of B cell linear epitopes

\begin{tabular}{llllll}
\hline Epitope no & Epitope sequence & Start & End & Epitope length & Percent of protein sequence matches at identity $<=100 \%$ \\
\hline 1 & MTAPSSGMAW & 83 & 92 & 10 & $\mathbf{8 9 . 1 3 \% ( 8 2 / 9 2 )}$ \\
2 & GGPI & 193 & 196 & 4 & $\mathbf{9 0 . 2 2 \% ( 8 3 / 9 2 )}$ \\
3 & 235 & 240 & 6 & $\mathbf{9 7 . 8 3 \% ( 9 0 / 9 2 )}$ \\
4 & TGNFSD & 352 & 359 & 8 & $\mathbf{9 4 . 5 7 \% ( 8 7 / 9 2 )}$ \\
6 & GPLQGGCK & 450 & 453 & 4 & $\mathbf{9 1 . 3 0 \% ( 8 4 / 9 2 )}$ \\
7 & DSAV & 488 & 494 & 7 & $\mathbf{9 6 . 7 4 \% ( 8 9 / 9 2 )}$ \\
8 & VNPCEDV & 512 & 518 & 7 & $\mathbf{9 4 . 5 7 \% ( 8 7 / 9 2 )}$ \\
9 & RNETGSQ & 642 & 646 & 5 & $\mathbf{8 1 . 5 2 \% ( 7 5 / 9 2 )}$ \\
10 & VGQKE & 656 & 665 & 10 & $\mathbf{8 1 . 5 2 \% ( 7 5 / 9 2 )}$ \\
11 & STKPAGFNTP & 926 & 931 & 6 & $\mathbf{9 8 . 9 1 \% ( 9 1 / 9 2 )}$ \\
12 & PQNAPN & 959 & 964 & 6 & $\mathbf{9 8 . 9 1 \% ( 9 1 / 9 2 )}$ \\
13 & ANASQY & 966 & 969 & 4 & $\mathbf{8 6 . 9 6 \% ( 8 0 / 9 2 )}$ \\
14 & IVPA & 1026 & 1030 & 5 & $\mathbf{8 4 . 7 8 \% ( 7 8 / 9 2 )}$ \\
15 & DFDFN & 1034 & 1045 & 12 & $\mathbf{9 4 . 5 7 \% ( 8 7 / 9 2 )}$ \\
\hline
\end{tabular}

used to examine the trans-membrane topology of S protein. Presence of disulphide-bonds were predicted through an online tool DIANNA v1.1. It makes prediction based on trained neural system [18]. CDD-BLAST (http://www.ncbi.nlm.nih.gov/BLAST/) [19-21] and PFAM (https://pfam.xfam.org/) [22] were used to search the defined conserved domains in the targeted protein sequences. Blastp in NCBI database (https://blast.ncbi. nlm.nih.gov/Blast.cgi) using reference sequence (refseqprotein) database was used to compare spike reference sequences of different coronaviruses in human and animals against IBV spike protein sequence. Phylogenetic tree was also constructed based on COBALT multiple alignment (https://www.ncbi.nlm.nih.gov/blast/treeview/ treeView.cgi) [19, 20].

\section{Multiple sequence alignment and epitope conservancy assessment}

The retrieved sequences of IBV S protein were aligned using Clustal program and consensus sequence was generated using the multiple sequence alignment (MSA) tool, Jalview version 2.10.5. (http://www.jalview.org/about/jalviewscientific-advisory-committee) [23]. Epitope conservancy analysis in Immune Epitope Database (IEDB) was used to detect potential epitope conservancy (http://tools.iedb.org/ conservancy/) [24]. For calculating the conservancy score, the sequence identity threshold was kept at $80 \%$.

\section{Phylogeny analysis}

Phylogenetic tree of the retrieved sequences of spike (S) protein was performed using MEGA7.0.26 (7170509) software using maximum likelihood parameter [25].
Table $\mathbf{4}$ List of shortened B cell epitopes predicted by different $B$ cell scale

\begin{tabular}{|c|c|c|c|c|c|c|}
\hline No. & Peptide & Start & End & Length & Emini & koleskar \\
\hline 1 & MTAP & 83 & 86 & 4 & 0.949 & 0.966 \\
\hline 2 & GSRIQT & 406 & 411 & 6 & 1.273 & 0.973 \\
\hline 3 & SRIQT & 407 & 411 & 5 & 1.583 & 0.992 \\
\hline 4 & SRIQ & 407 & 410 & 4 & 1.355 & 1.013 \\
\hline 5 & STKP & 656 & 659 & 4 & 2.543 & 0.979 \\
\hline 6 & VGLP & 704 & 707 & 4 & 0.398 & 1.143 \\
\hline 7 & VGLPT & 704 & 708 & 5 & 0.465 & 1.096 \\
\hline 8 & NASQY & 960 & 964 & 5 & 2.034 & 1.006 \\
\hline 9 & SKWW & 1034 & 1037 & 4 & 1.26 & 0.932 \\
\hline 10 & KKSSYYTT & 1139 & 1146 & 8 & 6.723 & 1.003 \\
\hline 11 & KSSYYTT & 1140 & 1146 & 7 & 4.166 & 1.013 \\
\hline 12 & SSYYTT ${ }^{a}$ & 1141 & 1146 & 6 & 2.568 & 1.027 \\
\hline 13 & SYYTT & 1142 & 1146 & 5 & 2.359 & 1.03 \\
\hline 14 & YYTT ${ }^{a}$ & 1143 & 1146 & 4 & 1.26 & 1.035 \\
\hline 15 & KKSSYYT & 1139 & 1145 & 7 & 5.773 & 1.016 \\
\hline 16 & KKSSYY & 1139 & 1144 & 6 & 4.931 & 1.034 \\
\hline 17 & KSSYYT & 1140 & 1145 & 6 & 3.559 & 1.031 \\
\hline 18 & KKSSY & 1139 & 1143 & 5 & 3.875 & 1.009 \\
\hline 19 & KKSS & 1139 & 1142 & 4 & 3.054 & 0.971 \\
\hline 20 & SSYYT ${ }^{a}$ & 1141 & 1145 & 5 & 2.191 & 1.051 \\
\hline 21 & SYYT & 1142 & 1145 & 4 & 2.019 & 1.061 \\
\hline
\end{tabular}

${ }^{a}$ Shortened peptide that has high score in both Emini and kolaskar 
Table 5 Discontinuous epitopes predicted through DISCOTOPE 2.0 Server

\begin{tabular}{|c|c|c|c|c|}
\hline $\begin{array}{l}\text { Residue } \\
\text { ID }\end{array}$ & $\begin{array}{l}\text { Residue } \\
\text { Name }\end{array}$ & $\begin{array}{l}\text { Contact } \\
\text { Number }\end{array}$ & $\begin{array}{l}\text { Propensity } \\
\text { Score }\end{array}$ & $\begin{array}{l}\text { Discotope } \\
\text { Score }\end{array}$ \\
\hline 262 & SER & 2 & -3.91 & -3.69 \\
\hline 263 & VAL & 4 & -2.626 & -2.784 \\
\hline 264 & ASN & 0 & -0.238 & -0.211 \\
\hline 265 & THR & 19 & -1.418 & -3.44 \\
\hline 266 & THR & 5 & 0.483 & -0.148 \\
\hline 267 & PHE & 25 & -0.627 & -3.43 \\
\hline 268 & THR & 7 & -0.463 & -1.215 \\
\hline 387 & GLY & 1 & -3.678 & -3.37 \\
\hline 414 & GLU & 7 & -0.476 & -1.226 \\
\hline 415 & PRO & 8 & 0.187 & -0.754 \\
\hline 417 & VAL & 5 & -0.324 & -0.862 \\
\hline 419 & THR & 6 & 1.351 & 0.506 \\
\hline 420 & ARG & 0 & 1.529 & 1.353 \\
\hline 421 & HIS & 11 & 0.482 & -0.838 \\
\hline 422 & ASN & 12 & -2.504 & -3.596 \\
\hline 515 & THR & 4 & -3.071 & -3.178 \\
\hline 531 & GLY & 5 & -1.472 & -1.877 \\
\hline 532 & THR & 5 & 1.933 & 1.136 \\
\hline 533 & ARG & 0 & 1.404 & 1.243 \\
\hline 534 & ARG & 0 & -0.425 & -0.376 \\
\hline 648 & MET & 5 & -1.103 & -1.551 \\
\hline 649 & GLU & 16 & -1.752 & -3.39 \\
\hline 650 & LEU & 26 & -4.013 & -6.541 \\
\hline 651 & LEU & 10 & -2.379 & -3.256 \\
\hline 652 & ASN & 12 & -1.72 & -2.902 \\
\hline 655 & SER & 7 & -2.994 & -3.454 \\
\hline 685 & SER & 0 & -3.842 & -3.4 \\
\hline 741 & ILE & 15 & -1.303 & -2.878 \\
\hline 893 & GLN & 7 & -2.411 & -2.939 \\
\hline 896 & GLU & 9 & -2.901 & -3.602 \\
\hline
\end{tabular}

\section{B cell prediction}

The Immune Epitope Database (IEDB) (http://tools.iedb. org/mhci/) was used to predict B and T cell epitopes of IBV reference sequence of S protein (NP_040831.1) [26]. Linear B-cell epitopes were predicted using BepiPred from IEDB [27]. Emini surface accessibility prediction tool was used to predict surface located epitopes [28]. Whereas, the antigenic epitopes were investigated using kolaskar and Tongaonkar antigenicity method [29].

Discontinuous epitopes were predicted using DiscoTope server [30]. The parameter was set at $\geq 0.5$ which indicated $90 \%$ specificity and $23 \%$ sensitivity. This method is based on surface accessibility and amino acid

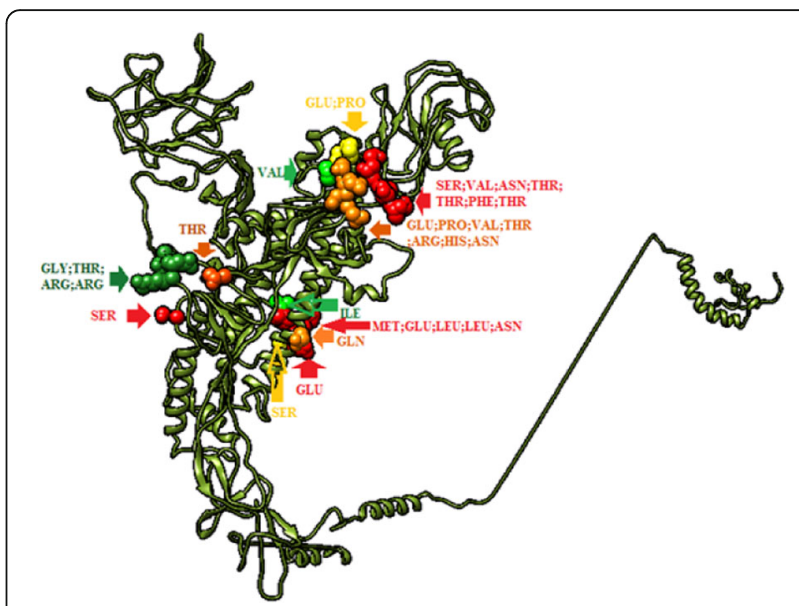

Fig. 5 The position of proposed discontinuous B cell epitopes in the 3D structure of spike protein of IBV illustrated by UCSF-Chimera visualization tool

statistics in a collected form dataset of discontinuous epitopes found out by X-ray crystallography of antigen/ antibody protein buildings. Chimera software was used to display the position of predicted epitopes clusters on 3D structure of S protein [31].

\section{T-cell epitope prediction}

The $\mathrm{T}$ cell epitopes were predicted in human among different alleles of major histocompatibility complex class I (MHCI) and class II (MHCII).

MHC-I binding epitopes were predicted by the IEDB MHC I prediction tool at http://tools.iedb.org/mhci. The binding affinity of peptides to MHC I molecules was

Table 6 Antigenic, non-allergic and non-toxic $\mathrm{MHCl}$ epitopes

\begin{tabular}{|c|c|c|c|c|c|}
\hline Peptide & Start & End & Antigenicity & Allele & ic50 \\
\hline \multirow[t]{3}{*}{ YYITARDMY } & 982 & 990 & 0.8845 & HLA-A*29:02 & 14.52 \\
\hline & & & & HLA-A*30:02 & 160.94 \\
\hline & & & & HLA-C*14:02 & 27.32 \\
\hline \multirow[t]{7}{*}{ YITARDMYM } & 983 & 991 & 0.7901 & HLA-A*02:01 & 233.08 \\
\hline & & & & HLA-A*02:06 & 212.86 \\
\hline & & & & HLA-C*03:03 & 29 \\
\hline & & & & HLA-C*06:02 & 200.39 \\
\hline & & & & HLA-C*07:01 & 267.22 \\
\hline & & & & HLA-C*14:02 & 49.52 \\
\hline & & & & HLA-C*15:02 & 77.63 \\
\hline \multirow[t]{3}{*}{ TARDMYMPR } & 985 & 993 & 0.6914 & HLA-A*30:01 & 56.23 \\
\hline & & & & HLA-A*31:01 & 14.3 \\
\hline & & & & HLA-A*68:01 & 28.24 \\
\hline \multirow[t]{2}{*}{ IIFILILGW } & 1105 & 1113 & 0.6749 & HLA-B*57:01 & 78.45 \\
\hline & & & & HLA-B*58:01 & 64.27 \\
\hline KKSSYYTTF & 1139 & 1147 & 1.1865 & HLA-A*32:01 & 182.52 \\
\hline
\end{tabular}


Table 7 Antigenic, non-allergic and non-toxic MHCll epitopes

\begin{tabular}{|c|c|c|c|c|c|c|}
\hline Core Sequence & Antigenicity & Peptide Sequence & Start & End & Allele & $1 \mathrm{IC50}$ \\
\hline IIFILILGW & 0.6914 & IAFATIIFILILGWV & 1100 & 1114 & HLA-DRB1*15:01 & $\overline{454.6}$ \\
\hline \multirow[t]{8}{*}{ KKSSYYTTF } & 0.6749 & MSKCGKKSSYYTTFD & 1134 & 1148 & HLA-DPA $1 * 01: 03 / D P B 1 * 02: 01$ & 872.7 \\
\hline & & SKCGKKSSYYTTFD & 1135 & 1149 & HLA-DPA $1 * 01 / D P B 1 * 04: 01$ & 408.1 \\
\hline & & & & & HLA-DPA $1 * 01: 03 / D P B 1 * 02: 01$ & 301.5 \\
\hline & & & & & HLA-DPA 1*02:01/DPB1*05:01 & 953.4 \\
\hline & & KCGKKSSYYTTFDND & 1136 & 1150 & HLA-DPA $1 * 01 / D P B 1 * 04: 01$ & 276.8 \\
\hline & & & & & HLA-DPA $1 * 02: 01 / D P B 1 * 05: 01$ & 853.9 \\
\hline & & CGKKSSYYTTFDNDV & 1137 & 1151 & HLA-DPA $1 * 02: 01 / D P B 1 * 05: 01$ & 958.9 \\
\hline & & MSKCGKKSSYYTTFD & 1134 & 1148 & HLA-DPA ${ }^{*} 01: 03 / D P B 1 * 02: 01$ & 872.7 \\
\hline \multirow[t]{6}{*}{ KSSYYTTFD } & 0.6466 & MSKCGKKSSYYTTFD & 1134 & 1148 & HLA-DRB1*04:05 & 155 \\
\hline & & SKCGKKSSYYTTFDN & 1135 & 1149 & HLA-DRB1*04:05 & 125.6 \\
\hline & & KCGKKSSYYTTFDND & 1136 & 1150 & HLA-DRB1*04:05 & 92.2 \\
\hline & & CGKKSSYYTTFDNDV & 1137 & 1151 & HLA-DRB1*04:05 & 51.9 \\
\hline & & GKKSSYYTTFDNDW & 1138 & 1152 & HLA-DRB1*04:05 & 46.9 \\
\hline & & KKSSYYTTFDNDWT & 1139 & 1153 & HLA-DRB1*04:05 & 45.3 \\
\hline \multirow[t]{3}{*}{ TARDMYMPR } & 0.7901 & SYYITARDMYMPRAI & 981 & 995 & HLA-DRB1*03:01 & 269.3 \\
\hline & & YYITARDMYMPRAIT & 982 & 996 & HLA-DRB1*03:01 & 281.9 \\
\hline & & YITARDMYMPRAITA & 983 & 997 & HLA-DRB1*03:01 & 618.8 \\
\hline \multirow[t]{26}{*}{ YITARDMYM } & 1.1865 & QVNGSYYITARDMYM & 977 & 991 & HLA-DRB1*01:01 & 22 \\
\hline & & & & & HLA-DRB1*04:01 & 145 \\
\hline & & & & & HLA-DRB1*04:04 & 331.2 \\
\hline & & & & & HLA-DRB1*07:01 & 20.3 \\
\hline & & & & & HLA-DRB3*01:01 & 550.7 \\
\hline & & & & & HLA-DRB5*01:01 & 227.8 \\
\hline & & VNGSYYITARDMYMP & 978 & 992 & HLA-DQA $1 * 01: 02 / D Q B 1 * 06: 02$ & 338.6 \\
\hline & & & & & HLA-DRB1*01:01 & 25.8 \\
\hline & & & & & HLA-DRB1*03:01 & 447.6 \\
\hline & & & & & HLA-DRB1*04:01 & 105.8 \\
\hline & & & & & HLA-DRB1*04:04 & 248.3 \\
\hline & & & & & HLA-DRB1*07:01 & 27.8 \\
\hline & & & & & HLA-DRB1*15:01 & 380.6 \\
\hline & & & & & HLA-DRB3*01:01 & 577.8 \\
\hline & & & & & HLA-DRB5*01:01 & 198.6 \\
\hline & & NGSYYITARDMYMPR & 979 & 993 & HLA-DQA $1 * 01: 02 / D Q B 1 * 06: 02$ & 393.3 \\
\hline & & & & & HLA-DQA $1 * 05: 01 / D Q B 1 * 03: 01$ & 817.3 \\
\hline & & & & & HLA-DRB1*01:01 & 19.8 \\
\hline & & & & & HLA-DRB1*03:01 & 176.5 \\
\hline & & & & & HLA-DRB1*04:01 & 65.2 \\
\hline & & & & & HLA-DRB1*04:04 & 225 \\
\hline & & & & & HLA-DRB1*07:01 & 40.2 \\
\hline & & & & & HLA-DRB1*15:01 & 291.2 \\
\hline & & & & & HLA-DRB3*01:01 & 635 \\
\hline & & & & & HLA-DRB5*01:01 & 93.5 \\
\hline & & GSYYITARDMYMPRA & 980 & 994 & HLA-DQA1*01:02/DQB1*06:02 & 218 \\
\hline
\end{tabular}


Table 7 Antigenic, non-allergic and non-toxic MHCll epitopes (Continued)

\begin{tabular}{|c|c|c|c|c|c|c|}
\hline Core Sequence & Antigenicity & Peptide Sequence & Start & End & Allele & $\mathrm{IC} 50$ \\
\hline & & & & & HLA-DRB 1*01:01 & 14 \\
\hline & & & & & HLA-DRB1*03:01 & 197.3 \\
\hline & & & & & HLA-DRB1*04:01 & 47.8 \\
\hline & & & & & HLA-DRB1*04:04 & 242.4 \\
\hline & & & & & HLA-DRB 1*07:01 & 57.3 \\
\hline & & & & & HLA-DRB1*15:01 & 288.6 \\
\hline & & & & & HLA-DRB3*01:01 & 780.4 \\
\hline & & & & & HLA-DRB5*01:01 & 61.4 \\
\hline & & SYYITARDMYMPRAI & 981 & 995 & HLA-DRB 1*01:01 & 23.1 \\
\hline & & & & & HLA-DRB1*04:01 & 65.3 \\
\hline & & & & & HLA-DRB1*04:04 & 249.2 \\
\hline & & & & & HLA-DRB1*04:05 & 356.4 \\
\hline & & & & & HLA-DRB1*07:01 & 72.2 \\
\hline & & & & & HLA-DRB1*15:01 & 284.7 \\
\hline & & & & & HLA-DRB5*01:01 & 87.4 \\
\hline & & YYITARDMYMPRAIT & 982 & 996 & HLA-DRB1*01:01 & 40.8 \\
\hline & & & & & HLA-DRB 1*04:01 & 108.8 \\
\hline & & & & & HLA-DRB1*04:04 & 269.1 \\
\hline & & & & & HLA-DRB1*04:05 & 706.3 \\
\hline & & & & & HLA-DRB1*07:01 & 160.6 \\
\hline & & & & & HLA-DRB5*01:01 & 121.3 \\
\hline & & YITARDMYMPRAITA & 983 & 997 & HLA-DRB1*04:01 & 145.4 \\
\hline & & & & & HLA-DRB1*04:04 & 652.4 \\
\hline & & & & & HLA-DRB1*07:01 & 355.4 \\
\hline & & & & & HLA-DRB 1*08:02 & 955 \\
\hline & & & & & HLA-DRB5*01:01 & 206.9 \\
\hline \multirow[t]{18}{*}{ YYITARDMY } & 0.8845 & IQVNGSYYITARDMY & 976 & 990 & HLA-DQA $1{ }^{*} 05: 01 / \mathrm{DQB} 1{ }^{*} 02: 01$ & 491.6 \\
\hline & & & & & HLA-DRB $1 * 04: 01$ & 723.4 \\
\hline & & & & & HLA-DRB $1 * 04: 04$ & 819.7 \\
\hline & & & & & HLA-DRB1*11:01 & 72 \\
\hline & & & & & HLA-DRB1*11:01 & 72 \\
\hline & & QVNGSYYITARDMYM & 977 & 991 & HLA-DPA1*01/DPB1*04:01 & 710.8 \\
\hline & & & & & HLA-DPA $1 * 01: 03 / D P B 1 * 02: 01$ & 875.8 \\
\hline & & & & & HLA-DQA $1 * 05: 01 / D Q B 1 * 02: 01$ & 292.7 \\
\hline & & & & & HLA-DRB1*03:01 & 588 \\
\hline & & & & & HLA-DRB $1 * 11: 01$ & 32.4 \\
\hline & & & & & HLA-DRB1*11:01 & 32.4 \\
\hline & & & & & HLA-DPA1*01/DPB1*04:01 & 557.6 \\
\hline & & & & & HLA-DPA $1 * 01: 03 / D P B 1 * 02: 01$ & 860.8 \\
\hline & & & & & HLA-DQA $1^{*} 05: 01 / \mathrm{DQB} 1^{*} 02: 01$ & 311.9 \\
\hline & & & & & HLA-DRB1*11:01 & 17.9 \\
\hline & & & & & HLA-DRB1*11:01 & 17.9 \\
\hline & & NGSYYITARDMYMPR & 979 & 993 & HLA-DPA $1 * 01 / D P B 1 * 04: 01$ & 503 \\
\hline & & & & & HLA-DPA1*01:03/DPB1*02:01 & 763.2 \\
\hline
\end{tabular}


Table 7 Antigenic, non-allergic and non-toxic MHCll epitopes (Continued)

\begin{tabular}{|c|c|c|c|c|c|c|}
\hline Core Sequence & Antigenicity & Peptide Sequence & Start & End & Allele & IC50 \\
\hline & & & & & HLA-DQA 1*05:01/DQB 1*02:01 & 387.6 \\
\hline & & & & & HLA-DRB1*09:01 & 858.7 \\
\hline & & & & & HLA-DRB 1*09:01 & 858.7 \\
\hline & & & & & HLA-DRB1*11:01 & 11 \\
\hline & & & & & HLA-DRB 1*11:01 & 11 \\
\hline & & GSYYITARDMYMPRA & 980 & 994 & HLA-DPA $1 * 01 / D P B 1 * 04: 01$ & 504.5 \\
\hline & & & & & HLA-DPA $1 * 01: 03 / D P B 1 * 02: 01$ & 790.4 \\
\hline & & & & & HLA-DQA 1*05:01/DQB 1*02:01 & 482.9 \\
\hline & & & & & HLA-DRB1*11:01 & 15.2 \\
\hline & & & & & HLA-DRB $1 * 11: 01$ & 15.2 \\
\hline & & SYYITARDMYMPRAI & 981 & 995 & HLA-DPA1*01/DPB1*04:01 & 480 \\
\hline & & & & & HLA-DPA1*01:03/DPB1*02:01 & 733.8 \\
\hline & & & & & HLA-DQA $1 * 05: 01 / D Q B 1 * 02: 01$ & 526.3 \\
\hline & & & & & HLA-DRB $1 * 11: 01$ & 26.8 \\
\hline & & & & & HLA-DRB1*11:01 & 26.8 \\
\hline & & YYITARDMYMPRAIT & 982 & 996 & HLA-DPA $1 * 01 / D P B 1 * 04: 01$ & 705.6 \\
\hline & & & & & HLA-DPA1*01:03/DPB1*02:01 & 931.5 \\
\hline & & & & & HLA-DQA $1 * 05: 01 / D Q B 1 * 02: 01$ & 678.7 \\
\hline & & & & & HLA-DRB1*11:01 & 51.8 \\
\hline & & & & & HLA-DRB1*11:01 & 51.8 \\
\hline
\end{tabular}

measured using artificial neural networks (ANN) method $[32,33]$. Prior to prediction, peptide lengths were set as 9 mers. The half maximum inhibitory concentration (IC50) values needed for the binding of peptide to MHC-I molecules were set less than or equal to $300 \mathrm{nM}$.

The IEDB MHCII prediction tool was used for MHC class II molecules at (http://tools.iedb.org/mhcii/) [26]. Human MHC class II alleles (HLA DR, HLADP and HLADQ) were used for MHCII binding predication. The $\mathrm{NN}$-align method was used with IC50 less or equal to $1000 \mathrm{nM}$ [34].

\section{Antigenicity, allergenicity and toxicity of epitopes}

VaxiJen v2.0 server was used to predict the antigenicity of the conserved regions (http://www.jenner.ac.uk/VaxiJen) [35]. The default prediction parameters and a threshold value of 0.4 were used. The in silico allergenicity prediction of epitopes was investigated using AllerTop v 2.0 (http://www.ddg-pharmfac.net/AllerTOP) [36]. While ToxiPred server was used to evaluate the toxicity of predicted epitopes. (http://crdd.osdd.net/ raghava/toxinpred/) [37].

\section{Homology modeling}

IBV reference sequence and the protein sequences of BF alleles (BF2 *2101 and BF2*0401) were submitted to
Raptor X server (http://raptorx.uchicago.edu/) to design their three D structures [38-40]. PEPFOLD3 server was used for the homology modelling of MHCI epitopes (http://bioserv.rpbs.univ-paris-diderot.fr/services/PEP-

FOLD3/) from amino acid sequences [41-43]. Chimera software 1.8 was used to visualize 3D structures of IBV spike $S$ protein reference sequence and BF alleles [31].

\section{Molecular docking}

To perform molecular docking, 3D structures of $\mathrm{MHCI}$ epitopes and BF alleles were submitted simultaneously to the PatchDock online autodock tools; an automatic server for molecular docking (https://bioinfo3d.cs.tau.ac. il/PatchDock/) [44]. The five top models were selected using firedock [44]. The results were visualized using the UCSF-Chimera software 1.8 [31].

\section{Results}

\section{Structural analysis}

The physiochemical properties of the spike S protein, measured through Protparam, showed that it contained 1162 amino acids (aa) with a molecular weight of 128 , $046.70 \mathrm{kDa}$. The spike protein showed an antigenic nature when subjected to Vaxijen v2.0.

Theoretical isoelectric point (PI) of spike protein was 7.71, indicating its positive in nature. An isoelectric point above 7 indicates the protein is charged positively. 
Near to 81 aa charges were found negative, whereas 84 aa found positive.

Protparam computed instability-index (II) 35.53, this categorize the protein as stable. Aliphatic-index 86.05, which devotes a thought to the proportional volume holding by aliphatic side chain and GRAVY value of the protein sequence is 0.012 . Half-life of $\mathrm{S}$ protein shown as the total time taken for its vanishing after it has been synthesized in cell, computed as $30 \mathrm{~h}$ for mammalianreticulocytes, $>20 \mathrm{~h}$ for yeast, $>10 \mathrm{~h}$ for Escherichia coli. The total numbers of Carbon (C), Oxygen (O), Nitrogen $(\mathrm{N})$, Hydrogen $(\mathrm{H})$ and Sulfur $(\mathrm{S})$ were entitled by the formula: $\mathrm{C}_{5737} \mathrm{H}_{8847} \mathrm{~N}_{1495} \mathrm{O}_{1718} \mathrm{~S}_{56}$.

The secondary structure of IBV spike $S$ protein was analyzed through PSIPRED and GOR IV server. The components of secondary structure prediction by GOR IV server are alpha helix (29.43\%), extended strand (27.37\%), beta turn (5.25\%), and random coil (37.95\%) (Fig.1).

DiANNA1.1 tool calculated 19 disulphides bond (S-S) positions and assign them a score and makes prediction based on trained neural system. The trans-membrane protein topology was investigated via online tool TMHMM. Residues from 1 to 1093 were found to be exposed to the surface, residue from 1094 to 1116 were found inside trans-membrane-region and residues from 1117 to 1162 were buried within the core-region of the $\mathrm{S}$ protein (Fig.1).

In refseq of IBV spike protein two conserved domains (Corona-S2, Corona-S2) were identified. The conserved domains were sequenced by Conserved Domain (CDD) BLAST search. The results revealed that corona-S1 (pfam01600) is the only member of the superfamily cl03276 and corona-S2 domain (pfam01601) is the only member of the superfamily cl20218. The top associated sequences in both domains were Feline infectious peritonitis virus (strain 79-1146), Avian infectious bronchitis virus (strain Beaudette), and Human coronavirus 229E while Severe acute respiratory syndrome-related coronavirus sequences were associated only with corona-S2 domain. The closest homologue obtained from BLASTP (refseq-protein) results was the Turkey coronavirus $S$ protein with $E$ value 0.00 followed by Murine hepatitis virus strain JHM with E value 9e-109 when comparing various coronaviruses in human and animals with IBV spike protein sequence (Table 2). Phylogenetic tree of IBV against other coronaviruses in human and animals was created based on COBALT multiple alignment see Fig. 2.

\section{Multiple sequence alignment}

Jalview was used to visualize the multiple sequence alignment of the retrieved sequences. Several areas in alignment were shown to have mutation see Fig. 3.

\section{Phylogeny}

Phylogenetic tree for IBV spike S protein sequences was constructed using MEGA7.0.26 (7170509) software using maximum likelihood parameter see Fig. 4.

\section{B-cell epitopes}

Several epitopes were predicted in B cell prediction methods using the Bepipred Linear Epitope Prediction tool. The conservancy percentages of these epitopes are presented in Table 3. After shortening of predicted epitopes, 21 linear conserved epitopes were recognized. Of these, seven epitopes with different lengths were identified as linear, surface and antigenic epitopes between the positions 1139-1146 (see Table 4). These epitopes were ${ }_{1139} K_{K S S Y Y}{ }_{1144,} \quad{ }_{1140} K_{S S Y Y T} T_{1145}, \quad{ }_{1141} S_{S Y Y T T} T_{1146}$, ${ }_{1141} S S Y Y T_{1145}, \quad{ }_{1142} S Y Y T T_{1146},{ }_{1142} S Y Y T_{1145}$, and ${ }_{1143} Y Y T T_{1146}$. Based on the length and antigenicity score, three epitopes ${ }_{1139} K K S S Y Y_{1144},{ }_{1140} K S S Y Y T_{1145}$, ${ }_{1141} \mathrm{SSYYT}_{1145}$ ) were selected as top B cell epitopes.

Discotope 2.0 server was used to predict the discontinuous epitopes from the 3D structure of $\mathrm{S}$ protein (PDB ID: 6CV0), 90\% specificity, -3.700 threshold and 22.000 Angstroms propensity score radius [45]. Total 30 discontinuous epitopes were recognized at different exposed surface areas (Table 5). The position of each predicted epitope on the surface of 3D structure of $\mathrm{S}$ protein is shown in Fig. 5 using Chimera visualization tool [31].

\section{Prediction of MHC class I epitopes}

In this study, the Human MHC class-I HLA alleles were used to explore the interaction of epitopes with $\mathrm{MHCI}$ alleles as chicken MHC alleles don't exists in IEDB database. MHC-1 binding prediction tool using IEDB database expected 13 conserved epitopes of spike protein (S) which were interacted with many cytotoxic $\mathrm{T}$ cell alleles. These epitopes were ${ }_{1115} F F M T G C C G C_{1123}$, $590 F N L T V T$ $D E Y_{598},{ }_{734} G L L V L P P I I_{742},{ }_{1105}$ IIFILILGW $_{1113},{ }_{1139} K K S S$ YYTTF $_{1147},{ }_{1087} K_{T Y I K W P W Y}{ }_{1095},{ }_{166} S V Y L N G D L V_{174}$, ${ }_{985} T_{A R D M Y M P R}{ }_{993},{ }_{1145} T_{T F D N D V V} T_{1153},{ }_{983}$ YITARD MYM $_{991}, \quad{ }_{1144} Y T T F D N D V V_{1152}, \quad{ }_{982} Y_{Y I T A R D M Y} Y_{990}$ ${ }_{1143} Y Y T T F D N D V_{1151}$.

\section{Prediction of MHC class II epitopes}

MHC-II binding prediction tool based on NN-align with half-maximal inhibitory concentration (IC50) $\leq 1000$ was used. Thirty one conserved core sequences were predicted to interact with MHCII alleles. These cores were ${ }_{694}$ EDLLFTSVE $_{702},{ }_{1147}$ FDNDVVTEQ $_{1155},{ }_{1115} F F M T G C$ $C_{1123},{ }_{1116} F M T G C C G C C_{1124}, \quad{ }_{590} F_{14 L T V T D E Y}{ }_{598}$, ${ }_{734}$ GLLVLPPII $_{742},{ }_{1105}$ IIFILILGW $_{1113},{ }_{902}$ INECVKSQS $_{910}$, ${ }_{984} I T A R D M Y M P_{992},{ }_{901} K I N E C V K S Q_{909},{ }_{1139} K K S S Y Y T T$

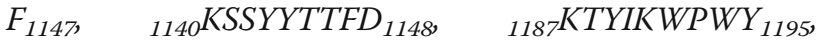
${ }_{735}$ LLVLPPIIT $_{743}, \quad{ }_{592}$ LTVTDEYIQ $_{600}, \quad{ }_{1014} N K T V I T$ 
$T F V_{1022} \quad{ }_{893} Q Q R E L A T Q K_{901}, \quad{ }_{894} Q_{R E L A T Q K I}{ }_{902}$, ${ }_{895}$ RELATQKIN $_{903}, \quad{ }_{589} S F N L T V T D E_{597}, \quad{ }_{1141} S S Y Y T T F D$ $N_{1149}, \quad{ }_{166} S V Y L N G D L V_{174}, \quad{ }_{1142} S Y Y T T F D N D_{1150}$,

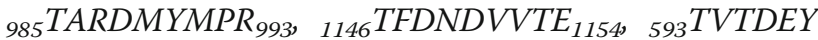
$I_{Q T} T_{601}, \quad{ }_{1013}$ VNKTVITTF $_{1021}, \quad{ }_{983}$ YITARDMYM $_{991}$, ${ }_{1144} Y T T F D N D V V_{1152}{ }_{982} Y_{Y I T A R D M} Y_{990}$ and ${ }_{1143} Y Y T T$ $F D N D V_{1151}$.

\section{Antigenicity, allergenicity and toxicity of $\mathrm{MHCl}$ and $\mathrm{MHCl}$ epitopes}

The predicted epitopes of MHCI and MHCII were subjected to VaxiJen v2.0 server, AllerJen v2.0. and ToxiPred to estimate the potential antigenicity, allergenicity and toxicity of epitopes. Five MHCI epitopes were identified as antigenic, non-allergic and non-toxic, but only three epitopes (985TARDMYMPR ${ }_{993},{ }_{983}$ YITARDMYM $_{991}$ and ${ }_{982}$ YYITARDM $\left.Y_{990}\right)$ showed a high linkage with MHCI alleles (Table 6). Furthermore, six MHCII epitopes were predicted to be antigenic, non-allergic and non-toxic epitopes (Table 7). However, ${ }_{983}$ YITARDMY $M_{991}$ and ${ }_{982} Y Y I T A R D M Y_{990}$ epitopes which were also presented in MHCII prediction methods, showed high antigenicity, no allergenicity and no toxicity. These epitopes were interacted with 52 and 38 alleles in MHCII see Fig. 6.

\section{Molecular docking}

The molecular docking was achieved by docking MHCI epitopes with chicken BF alleles (BF2 * 2101 \& BF2 * 0401) using peptide-binding groove affinity. The chicken alleles were used as receptors, and the top MHCI epitopes ${ }_{982} Y_{Y I T A R D M Y} Y_{990},{ }_{983} Y_{\text {YTARDMYM }}{ }_{991}$ and ${ }_{985}{ }^{T A R D M Y M P R} \mathrm{R}_{993}$ were used as ligands. Docking of

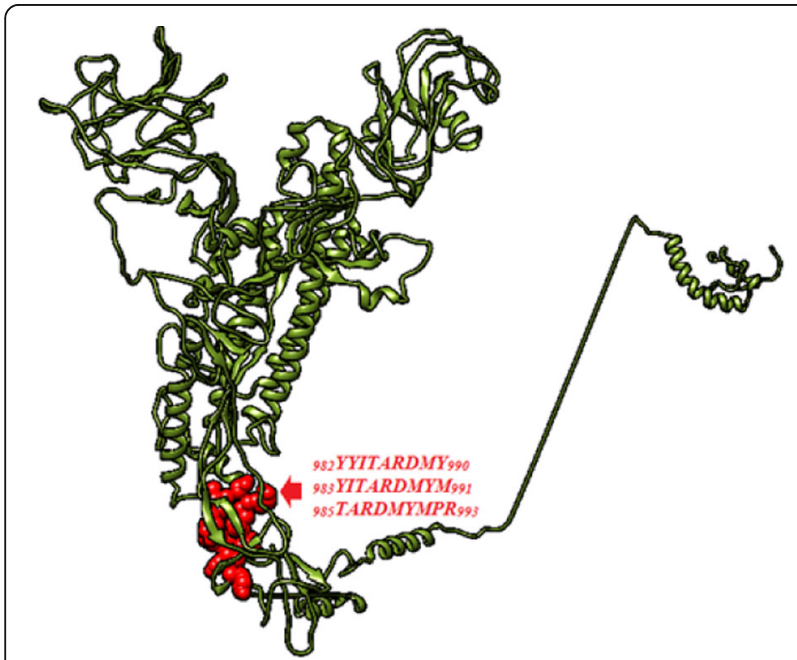

Fig. 6 The position of proposed $\mathrm{MHCl}$ and $\mathrm{MHCll}$ epitopes (sphere red colour) in the 3D structure of spike protein of IBV illustrated by UCSF-Chimera visualization tool
${ }_{983}$ YITARDMYM $_{991}$ epitope with BF2\%2101 and $\mathrm{BF}_{2}{ }^{*} 0401$ alleles showed -72.11 and -37.39 global energy respectively, indicating a strong binding affinity between the ligands and the receptors compared to other epitopes (Fig. 7, 8 and 9). In general, the global binding affinity of ligands with the receptor BF2*2101 alleles was found to be lower compared to BF2*0401, suggesting strong receptor-ligand interaction.

\section{Discussion}

Epitopes capable of inducing immunity in both types (Bcell and T-cell) are considered to be strong candidates for the vaccine [46]. There are several potential benefits offered by peptide vaccine over traditional vaccines against organisms. Most importantly, it allows the immune response to focus only on relevant epitopes and avoid those leading to non-protective responses, immune evasion, or unwanted side effects, such as autoimmunity [47].

IBV vaccination studies have always focused on humoral immune responses regarding protection. Acquired immunity results in the activation of antigenspecific effector mechanisms including B-cells (humoral), T-cells (cellular) and macrophages, and memory cells production [4]. Chickens develop a good humoral response to IBV infections, which measured by ELISA, virus neutralizing (VN) and haemagglutinationinhibition HI antibodies tests [48].

IBV glycoprotein S1 is known to be responsible for virus neutralization (VN) and haemagglutinationinhibition $\mathrm{HI}$ antibodies and has been considered the most likely protective inducer [4]. Multi-peptide vaccines using immunoinformatics tools have recently been conducted in Sudan for several viral diseases in chicken such as ILTV, fowlpox, Newcastle and marek's disease virus [15, 49-51].

In the present study, IBV spike protein was analyzed using various prediction servers. Protein characterization of IBV spike $S$ protein using Protparam confirmed its positive in nature and stable. The protein also exhibited good antigenic properties using Vaxijen 2.0v server.

Corona-S1 and Corona S2 have been identified as major conserved domains in the IBV spike glycoprotein refseq. Conserved Domain (CDD) BLAST search revealed that corona-S1 (pfam01600) is the only member of the superfamily cl03276 and corona-S2 domain (pfam01601) is the only member of the superfamily cl20218. The main related sequences in both domains were Feline infectious peritonitis virus (strain 79-1146), Avian infectious bronchitis virus (strain Beaudette), and Human coronavirus 229E. However, Severe acute respiratory syndrome-related coronavirus sequences was only associated with corona-S2 domain [52]. 

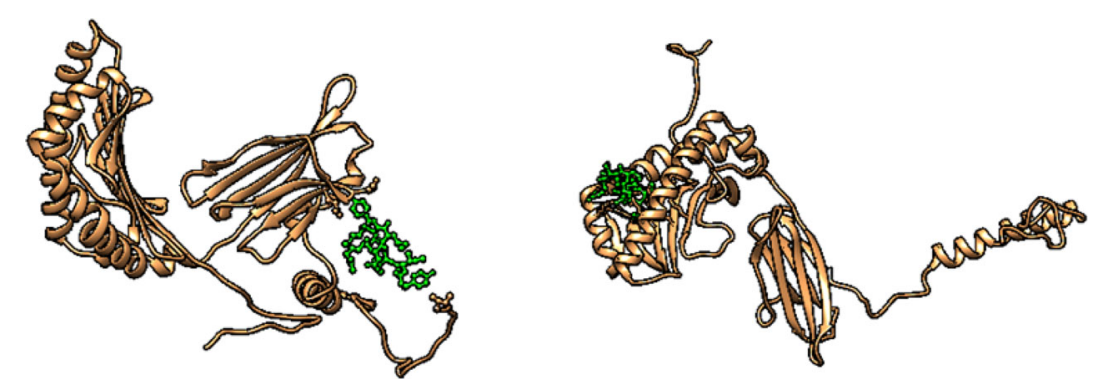

\begin{tabular}{lccc}
\hline Peptide & Receptor & Energy & Attractive vdw \\
\hline YITARDMYM & $\mathrm{BF}_{2} 2101$ & -72.11 & -37.79 \\
& $\mathrm{BF}_{2} 0401$ & -30.33 & -38.52 \\
\hline
\end{tabular}

Fig. 7 Docking of YITARDMYM with $\mathrm{BF}_{2}$ alleles

Prediction of B-cell epitopes is essential for the design vaccine components and immuno-diagnostic reagents. B-cell antigenic epitopes are either continuous or discontinuous in nature.

Most epitope prediction methods are based on continuous epitopes [53]. It has been reported that linear B cell epitopes play a role in virus neutralization [11]. IEDB prediction tool was used to predict linear, surface and antigenic epitopes based on the properties of amino acids such as hydrophilicity, surface accessibility, flexibility, and antigenicity [15].

In this study, seven shortened conserved epitopes ${ }_{1139} K_{K K S Y Y} Y_{1144}, \quad{ }_{1140} K_{S S Y Y T}{ }_{1145}, \quad{ }_{1141} S_{S Y Y T T} T_{1146}$, ${ }_{1141} S S Y Y T_{1145},{ }_{1142} S Y Y T T_{1146},{ }_{1142} S Y Y T_{1145}$, and $\left.{ }_{1143} Y Y T T_{1146}\right)$ were predicted from $\mathrm{B}$ cell prediction methods as surface, linear and antigenic epitopes. The predicted epitopes were adjacent to each other from the position 1139-1146. In a similar study, only one epitope (YTSNETTDVTS $^{175-185}$ ) was predicted within the S1 glycoprotein of M41 IBV strains using BepiPred epitope prediction server version 1 , and three such epitopes (VSNASPNSGGVD ${ }^{279-290,}$ HPKCNFRPENI ${ }^{328-338}$, NETNNAGSVSDCTAGT ${ }^{54-69}$ ) were predicted in CR88 IBV strains [11].

The majority of B-cell epitopes are conformational (around a 90\%) and only a minority of native antigens have linear B-cell epitopes [54]. Discotope server has been used for predicting discontinuous.

Epitopes from the 3D structure of the spike IBV reference sequence. Around 30 discontinuous epitopes with a specificity of $90 \%$ were recognized at different exposed surface areas. These epitopes have a significant

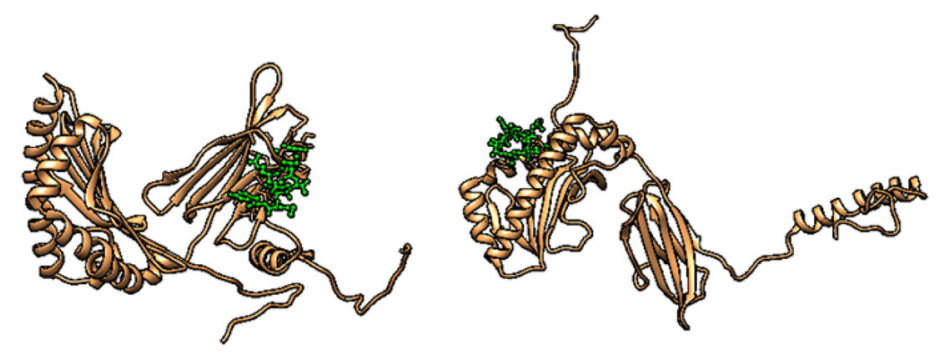

\begin{tabular}{lllc}
\hline Peptide & Receptor & Energy & Attractive vdw \\
\hline YYITARDMY & $\mathrm{BF}_{2} 2101$ & -64.68 & -35.26 \\
& $\mathrm{BF}_{2} 0401$ & -37.57 & -23.93 \\
\hline
\end{tabular}

Fig. 8 Docking of YYITARDMY with $\mathrm{BF}_{2}$ alleles 

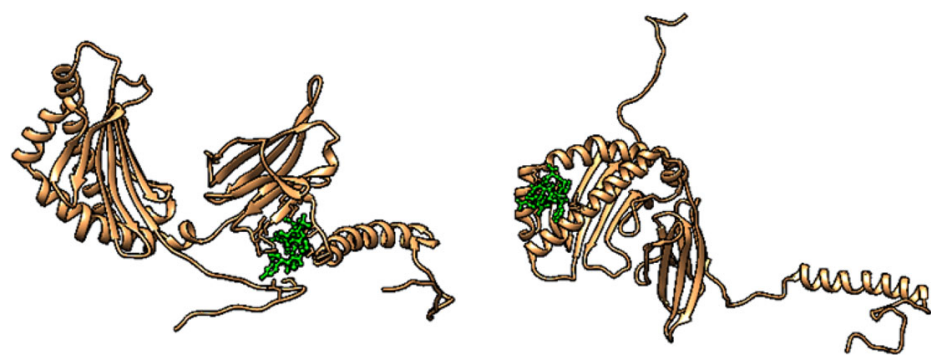

\begin{tabular}{lccc}
\hline Peptide & Receptor & Energy & Attractive vdw \\
\hline TARDMYMPR & $\mathrm{BF}_{2} 2101$ & -45.61 & -30.25 \\
& $\mathrm{BF}_{2} 0401$ & -35.47 & -28.81
\end{tabular}

Fig. 9 Docking of TARDMYMPR with $\mathrm{BF}_{2}$ alleles

advantage in identifying the native well-structured protein Ag [55].

Cytotoxic T lymphocytes (CTL) provide a critical arm of the immune system in eliminating autologous cells expressing foreign antigen. Unlike humoral immunity, the specificity of CTL activation depends on membrane receptors rather than secreted molecules, and antigen receptors of CTL interact with peptide determinants only in association with matched major histocompatibility complex (MHC) molecules. Virusspecific CTL have been shown to be important, if not critical, for resolution of infection and elimination of viral shedding [1].

It is stated that, the major histocompatibility complex MHC restricted CTL response can be associated with decreases in viral load, and $\mathrm{CD} 8^{+}$lymphocytes were mostly responsible for the observed protection $[1,56]$. Responses to infectious bronchitis virus (IBV) with cytotoxic T-lymphocyte (CTL) were calculated at regular intervals between 3 and 30 days post infection [1].

However, MHCI prediction methods showed three conserved CTL epitopes ${ }_{985} T_{A R D M Y M P R}{ }_{993},{ }_{983} Y I T A$ $R D M Y M_{991}$ and ${ }_{982} Y_{Y I T A R D M} Y_{990}$ as they linked to 7 and 3 human MHCI alleles respectively and showed high antigenicity, no allergenicity and no toxicity. Recent studies showed that vigorous cytotoxic $\mathrm{T}$ lymphocyte (CTL) responses that correlate with initial decrease in infection and illness can be detected after IBV infection. It has been identified that the $\mathrm{CD}^{+} \mathrm{T}$ cells were exhausted without $\mathrm{CD} 4^{+}$helper $\mathrm{T}$ cells. $\mathrm{CD} 4^{+} \mathrm{T}$ cells do not seem important in the initial resolution of IBV infection in chickens [56].

In MHCII prediction method, several core peptides were predicted to interact with $\mathrm{MHCII}$ alleles, but surprisingly the top core peptides were also ${ }_{983}$ YITARDMY $M_{991}$ and ${ }_{982} Y Y I T A R D M Y_{990}$ which were presented in
MHCI prediction methods. They linked with 52 and 38 human alleles respectively. These epitopes showed high antigenicity, no allergincity and no toxicity.

Molecular docking was performed to display the interaction between BF alleles (BF2*2101 \& BF2*0401) and MHCI epitopes (982 YYITARDMY ${ }_{990,}$ 983 YITARD $M Y M_{991}$ and ${ }_{985}$ TARDMYMPR $\left._{993}\right)$. The $3 \mathrm{D}$ structures of MHC I epitopes were designed using PEPFOLD and docked with BF alleles via Patchdock server. Docking the epitope ${ }_{983} Y_{T T A R D M Y M_{991}}$ with both BF2 alleles produced strong binding affinity $(-72.11$ and - 37.97 global energy respectively) followed by ${ }_{982}$ YYTTARDM $_{990}$ (-64.68 and -37.57 global energy respectively). This indicates the strong interaction between the ligand and the receptor compared to other epitopes (see Figs. 5, 6 and 7).

Ligands' interaction with the receptor BF2*2101 alleles was found to be better compared with BF2 *0401. However for both BF alleles, the docked molecules showed different groove binding site. Future studies should test the predicted epitopes for therapeutic potency to prove their safety and effectiveness.

\section{Conclusion}

In this study, five epitopes were predicted from spike glycoprotein of IBV as the best B cell ${ }_{1139} K K S S Y Y_{1144}$, ${ }_{1140} K S S Y Y T_{1145}$ and $\left.{ }_{1141} S S Y Y T_{1145}\right)$ and $\mathrm{T}$ cell epitopes $\left({ }_{982} Y_{Y I T A R D M} Y_{990}\right.$ and $\left.{ }_{983} Y_{\text {YTARDMYM }}{ }_{991}\right)$. They showed high antigenicity, no allergenicity and no toxicity as well as great linkage of MHC epitopes with their alleles. The suggested epitopes should be designed, incorporated and tested as multi-epitopes vaccine against IBV. This vaccine may serve as a possible peptide vaccine to control IBV infection in chicken by inducing humoral and cellular responses. 
Peptide vaccination against IBV spike protein (S) can strongly replace traditional vaccines as it is designed to cover all strains in different serotypes, which can reduce recurring outbreaks and their associated massive economic losses.

\section{Abbreviations}

IB: Infectious bronchitis; IBV: Infectious Bronchitis Virus; IEDB: Immune Epitope Database; S: Spike; MHC: Major histocompatibility complex; BF: The genetic polymorphism of properdin factor B; refseq: Reference sequence; NCBI: National Central Biotechnology Information; MSA: Multiple sequence alignment; GRAVY: Grand average of hydropathicity; CDD: Conserved Domain Database; IC50: The half maximal inhibitory concentration; ANN: Artificial neural networks; NN-align: Artificial neural network-based alignment; HLA: The human leukocyte antigen; CTL: Cytotoxic T Iymphocytes

\section{Acknowledgements}

Not applicable.

\section{Authors' contributions}

Eman, A. Awadelkareem and Sumaia A. Ali designed this study, accomplished the experiments and analyze the results. Sumaia A. Ali interpreted the data and wrote the manuscript. The authors read and approved the final manuscript.

\section{Funding}

Not applicable.

\section{Availability of data and materials}

All the data supporting the findings are contained within the manuscript.

\section{Ethics approval and consent to participate}

Not applicable.

\section{Consent for publication}

Not applicable.

\section{Competing interests}

The authors declare that they have no competing interests.

All manuscripts must contain the following sections under the heading 'Declarations':

\section{Author details}

${ }^{1}$ Faculty of Veterinary Medicine, University of Khartoum, Khartoum, Sudan. ${ }^{2}$ Department of Veterinary Medicine and Surgery, College of Veterinary Medicine, Sudan University of Science and Technology, Khartoum, Sudan.

Received: 29 April 2020 Accepted: 6 July 2020

Published online: 27 August 2020

\section{References}

1. Seo SH, Collisson EW. Specific cytotoxic T lymphocytes are involved in in vivo clearance of infectious bronchitis virus. J Virol. 1997;71(7):5173-7.

2. Cavanagh D. Coronavirus avian infectious bronchitis virus. Vet Res. 2007; 38(2):281-97.

3. Ignjatovic J, Sapats S. Avian infectious bronchitis virus. Revue Sci Tech Office Int des Epizooties. 2000;19(2):493-501.

4. Raj GD, Jones R. Infectious bronchitis virus: immunopathogenesis of infection in the chicken. Avian Pathology. 1997;26(4):677-706.

5. Yang T, Wang H-N, Wang $X$, Tang J-N, Lu D, Zhang Y-F, et al. The protective immune response against infectious bronchitis virus induced by multiepitope based peptide vaccines. Biosci Biotechnol Biochem. 2009;0864:1-5.

6. Abro SH, Ullman K, Belák S, Baule C. Bioinformatics and evolutionary insight on the spike glycoprotein gene of QX-like and Massachusetts strains of infectious bronchitis virus. Virol J. 2012;9(1):211.

7. Abdel-Moneim A, Madbouly H, Gelb J, Ladman B. Isolation and identification of Egypt/Beni-Seuf/01 a novel genotype of infectious bronchitis virus. Vet Med J IZA. 2002;50(4):1065-78.
8. Mo M-L, Hong S-M, Kwon H-J, Kim I-H, Song C-S, Kim J-H. Genetic diversity of spike, $3 \mathrm{a}, 3 \mathrm{~b}$ and e genes of infectious bronchitis viruses and emergence of new recombinants in Korea. Viruses. 2013;5(2):550-67.

9. Miller MM, Taylor RL Jr. Brief review of the chicken major histocompatibility complex: the genes, their distribution on chromosome 16, and their contributions to disease resistance. Poultry Sci. 2016;95(2):375-92.

10. Shina T, Hosomichi K, Hanzawa K. Comparative genomics of the poultry major histocompatibility complex. Anim Sci J. 2006;77(2):151-62.

11. Bande F, Arshad SS, Hair Bejo M, Kadkhodaei S, Omar AR. Prediction and in silico identification of novel B-cells and T-cells epitopes in the S1-spike glycoprotein of M41 and CR88 (793/B) infectious bronchitis virus serotypes for application in peptide vaccines. Adv Bioinforma. 2016;2016:5484972.

12. Dash $R$, Das $R$, Junaid $M$, Akash MF, Islam A, Hosen SZ. In silico-based vaccine design against Ebola virus glycoprotein. Adv Appl Bioinform Chem. 2017;10:11.

13. Gaafar B, Ali SA, Abd-elrahman KA, Almofti YA. Immunoinformatics approach for multiepitope vaccine prediction from $\mathrm{H}, \mathrm{M}, \mathrm{F}$, and $\mathrm{N}$ proteins of Peste des Petits ruminants virus. J Immunol Res. 2019;2019:1-18.

14. Zheng J, Lin $X$, Wang $X$, Zheng L, Lan S, Jin S, Ou Z, Wu J. In silico analysis of epitope-based vaccine candidates against hepatitis $B$ virus polymerase protein. Viruses. 2017;9(5):112.

15. Ali SA, Almofti YA, Abd-elrahman KA. Immunoinformatics approach for multiepitopes vaccine prediction against glycoprotein B of avian infectious laryngotracheitis virus. Adv Bioinforma. 2019;2019:1-23.

16. Gasteiger EGA, Hoogland C, Ivanyi I, Appel RD, Bairoch A. ExPASy: the proteomics server for in-depth protein knowledge and analysis. Nucleic Acids Res. 2003;31:3784-8.

17. Buchan DWMF, Nugent TC, Bryson K, Jones DT. Scalable web services for the PSIPRED protein analysis workbench. Nucleic Acids Res. 2013:41:W349-57.

18. Ferre F, Clote P. Disulfide connectivity prediction using secondary structure information and diresidue frequencies. Bioinformatics. 2005;21(10):2336-46.

19. Altschul SF, Madden TL, Schäffer AA, Zhang J, Zhang Z, Miller W, et al. Gapped BLAST and PSI-BLAST: a new generation of protein database search programs. Nucleic Acids Res. 1997;25(17):3389-402

20. Marchler-Bauer A, Anderson JB, Derbyshire MK, DeWeese-Scott C, Gonzales NR, Gwadz M, Hao L, He S, Hurwitz DI, Jackson JD, Ke Z. CDD: a conserved domain database for interactive domain family analysis. Nucleic Acids Res. 2007;35:D237-40.

21. Eddy SR. Profile hidden Markov models. Bioinformatics (Oxford, England). 1998;14(9):755-63.

22. El-Gebali S, et al. The Pfam protein families database in 2019. Nucleic Acids Res. 2019;47(D1):D427-32.

23. Waterhouse AM, Procter JB, Martin DM, Clamp M, Barton GJ. Jalview version 2-a multiple sequence alignment editor and analysis workbench. Bioinformatics. 2009;25(9):1189-91.

24. Bui H-H, Sidney J, Li W, Fusseder N, Sette A. Development of an epitope conservancy analysis tool to facilitate the design of epitope-based diagnostics and vaccines. BMC Bioinformatics. 2007:8(1):361.

25. Kumar S, Stecher G, Tamura K. MEGA7: molecular evolutionary genetics analysis version 7.0 for bigger datasets. Mol Biol Evol. 2016;33(7):1870-4.

26. Vita R, Overton JA, Greenbaum JA, Ponomarenko J, Clark JD, Cantrell JR, et al. The immune epitope database (IEDB) 3.0. Nucleic Acids Res. 2014; 43(D1):D405-D12.

27. Larsen JE, Lund O, Nielsen M. Improved method for predicting linear B-cell epitopes. Immunome Res. 2006;2(1):2.

28. Emini EA, Hughes $\mathrm{N}$, Perlow D, Boger J. Induction of hepatitis a virus-neutralizing antibody by a virus-specific synthetic peptide. J Virol. 1985;55(3):836-9.

29. Kolaskar A, Tongaonkar PC. A semi-empirical method for prediction of antigenic determinants on protein antigens. FEBS Lett. 1990;276(1-2): $172-4$.

30. Sun P, Ju H, Liu Z, Ning Q, Zhang J, Zhao X, et al. Bioinformatics resources and tools for conformational B-cell epitope prediction. Comput Math Methods Med. 2013:2013:943636.

31. Chan WM, Rogers SE, Nash SM, Buning PG, Meakin R. User's manual for Chimera grid tools, version 1.8. NASA Ames Research Center, URL: http:// people.nas.nasa.gov/ rogers/cgt/doc/man.html. 2003.

32. Patronov A, Doytchinova I. T-cell epitope vaccine design by immunoinformatics. Open Biol. 2013;3(1):120139.

33. Abdelbagi M, Hassan T, Shihabeldin M, Bashir S, Ahmed E. Immunoinformatics prediction of peptide-based vaccine against African horse sickness virus. Immunome Res. 2017;13(135):2.

34. Nielsen M, Lund O, et al. BMC Bioinformatics. 2009;10(1):296. 
35. Doytchinova IA, Flower DR. VaxiJen: a server for prediction of protective antigens, tumour antigens and subunit vaccines. BMC Bioinformatics. 2007;8(1):1-7.

36. Dimitrov I, Bangov I, Flower DR, Doytchinova I. AllerTOP v. 2-a server for in silico prediction of allergens. J Mol Model. 2014;20(6):2278 1-6.

37. Gupta S, Kapoor P, Chaudhary K, Gautam A, Kumar R, Raghava GP, et al. In silico approach for predicting toxicity of peptides and proteins. PLoS One. 2013;8(9):1-10.

38. Källberg M, Wang $\mathrm{H}$, Wang $\mathrm{S}$, Peng J, Wang Z, Lu H, et al. Template-based protein structure modeling using the RaptorX web server. Nat Protoc. 2012; 7(8):1511-22.

39. Peng J, Xu J. RaptorX: exploiting structure information for protein alignment by statistical inference. Proteins. 2011;79(S10):161-71.

40. Peng J, Xu J. A multiple-template approach to protein threading. Proteins. 2011;79(6):1930-9.

41. Maupetit J, Derreumaux P, Tufféry P. A fast method for large-scale De novo peptide and miniprotein structure prediction. J Comput Chem. 2010;31(4): 726-38.

42. Beaufays J, Lins L, Thomas A, Brasseur R. In silico predictions of 3D structures of linear and cyclic peptides with natural and non-proteinogenic residues. J Pept Sci. 2012;18(1):17-24.

43. Shen Y, Maupetit J, Derreumaux P, Tufféry P. Improved PEP-FOLD approach for peptide and miniprotein structure prediction. J Chem Theory Comput. 2014;10(10):4745-58

44. Andrusier N, Nussinov $\mathrm{R}$, Wolfson HJ. FireDock: fast interaction refinement in molecular docking. Proteins. 2007;69(1):139-59.

45. Shang J, Zheng Y, Yang Y, Liu C, Geng Q, Luo C, et al. Cryo-EM structure of infectious bronchitis coronavirus spike protein reveals structural and functional evolution of coronavirus spike proteins. PLoS Pathog. 2018;14(4): $1-9$

46. Verma SK, Yadav S, Kumar A. In silico prediction of B-and T-cell epitope on Lassa virus proteins for peptide based subunit vaccine design. Adv Biomed Res. 2015;4:201.

47. Reche PA, Fernandez-Caldas E, Flower DR, Fridkis-Hareli M, Hoshino Y. Peptide-based immunotherapeutics and vaccines. J Immunol Res. 2014; 2014:1-2.

48. Sylvester SA, Dhama K, Kataria J, Rahul S, Mahendran M. Avian infectious bronchitis: a review. Indian J Comp Microbiol Immunol Infect Dis. 2005:26:1-14.

49. Idris S, Salih S, Basheir M, Elhadi A, Kamel S, Abd-elrahman K, et al. In silico prediction of peptide based vaccine against Fowlpox virus (FPV). Immunome Res. 2018;14(2):1-11.

50. Badawi MM, Fadl Alla A, Alam SS, Mohamed WA, Osman D, Alrazig Ali S, et al. Immunoinformatics predication and in silico modeling of epitopebased peptide vaccine against virulent Newcastle disease viruses. Am J Infect Dis Microbiol. 2016:4(3):61-71

51. Bashir S, Abd-elrahman KA, Hassan MA, Almofti YA. Multi epitope based peptide vaccine against Marek's disease virus serotype 1 glycoprotein $\mathrm{H}$ and B. Am J Microbiol Res. 2018;6(4):124-39.

52. Gen J. Cloning and sequencing of the gene encoding the spike protein of the coronavirus IBV. J Gen Virol. 1985;66:719-26.

53. Yao B, Zheng D, Liang S, Zhang C. Conformational B-cell epitope prediction on antigen protein structures: a review of current algorithms and comparison with common binding site prediction methods. PLoS One. 2013;8(4):1-4.

54. Sanchez-Trincado JL, Gomez-Perosanz M, Reche PA. Fundamentals and methods for T-and B-cell epitope prediction. J Immunol Res. 2017;2017: $1-14$

55. Demolombe V, de Brevern AG, Felicori L, NGuyen C, de Avila RAM. Valera L, et al. PEPOP 2.0: new approaches to mimic non-continuous epitopes. BMC Bioinformatics. 2019;387:1-14.

56. Pei J, Briles WE, Collisson EW. Memory T cells protect chicks from acute infectious bronchitis virus infection. Virology. 2003;306(2):376-84.

\section{Publisher's Note}

Springer Nature remains neutral with regard to jurisdictional claims in published maps and institutional affiliations.

\section{Ready to submit your research? Choose BMC and benefit from:}

- fast, convenient online submission

- thorough peer review by experienced researchers in your field

- rapid publication on acceptance

- support for research data, including large and complex data types

- gold Open Access which fosters wider collaboration and increased citations

- maximum visibility for your research: over $100 \mathrm{M}$ website views per year

At BMC, research is always in progress.

Learn more biomedcentral.com/submissions 